УДК 556.161:556.166

\title{
СРАВНИТЕЛЬНЫЙ АНАЛИЗ МЕТОДИК ПРОГНОЗА МАКСИМАЛЬНЫХ УРОВНЕЙ И ОБЪЕМА СТОКА ПЕРИОДА ПОЛОВОДЬЯ ГОРНОЙ РЕКИ
}

\author{
Галахов Владимир Прокопьевич1, \\ galahov@iwep.ru

\section{Ловцкая Ольга Вольфовна 1 ,} \\ lov@iwep.ru
}

\section{Самойлова Светлана Юрьевна' ${ }^{1}$ bastet05@list.ru}

\author{
Мардасова Елена Владимировна², \\ mardasova_ev@mail.ru \\ 1 Институт водных и экологических проблем СО РАН, \\ Россия, 656038, г. Барнаул, ул. Молодежная, 1. \\ 2 Алтайский государственный университет, \\ Россия, 656049, г. Барнаул, пр. Ленина, 61.
}

\begin{abstract}
Актуальность работы обусловлена необходимостью анализа методов, используемых для оценки снегозапасов в речных бассейнах и прогнозирования половодья. В условиях недостаточности гидрометеорологической инфрормации для прогноза объёма и максимальных уровней половодья, как правило, используются статистические модели, основанные на корреляционной зависимости параметров стока от снегозапасов, либо уравнения множественной линейной регрессии. При этом нет обоснованного сравнения традиционных методов прогноза, основанных на расчете суммы зимних осадков (снегозапасов), и статистических моделей множественной регрессии.

Цель: сравнительный анализ методик расчета сумм зимних осадков в бассейне по традиционно применяемым высотным зависимостям и по авторской методике при помощи орографической добавки к скорости вертикальных движений воздушных масс; сравнительный анализ традиционных статистических методов прогноза и моделей множественной линейной регрессии на примере бассейна реки Амыл.

Методы: комплексный географоо-гидрометеорологический анализ; выявление зависимостей по данным многолетних гидрометеорологических наблюдений с использованием методов математической статистики (корреляционный и регрессионный анализ); моделирование снегозапасов с использованием орографической добавки к скорости вертикальных движений.

Результаты. В результате использования двух разных подходов к определению сумм зимних осадков (по высотным зависимостям и с помощью орографической добавки к скорости вертикальных движений воздушных масс) получены идентичные статистические зависимости с близкими коэфффициентами детерминации. Разработаны модели прогноза объема стока и максимальных уровней половодья на основе парной корреляции и с использованием множественного регрессионного анализа. Сравнительный анализ традиционных методов прогноза слоя стока, основанных на расчете суммы зимних осадков (снегозапасов), и статистических моделей множественной регрессии также показал идентичность результатов. Для прогноза максимальных уровней воды, вызванных таянием снега, предпочтительнее использование однофракторных зависимостей.
\end{abstract}

Ключевые слова:

Река Енисей, Западный Саян, река Туба, бассейн реки Амыл, зимние осадки, снегозапасы, высотная зависимость, орограффическая добавка к скорости вертикальных движений, статистическая модель множественной регрессии.

\section{Введение}

Объем стока и высокие уровни половодья в условиях длительной зимы обоснованы снегозапасами в конце зимы, интенсивностью снеготаяния, жидкими осадками периода половодья, степенью увлажнения и промерзания почвогрунтов бассейна в период снеготаяния [1-6].

Однако, как многократно указывали отечественные и зарубежные гидрологи [7-10], в горных бассейнах прогнозы стока и максимальных уровней периода половодья слабо обеспечены гидрометеорологической информацией. Метеорологические станции и гидрологические посты, фиксирующие увлажнение (количество осадков), расположены в речных долинах и не отражают условия увлажнения склонов и водораздельных пространств. В этой связи весьма показательно мнение К.Г. Колльера: «В настоящее время многие гидрологи приходят к выводу, что все более усложняющееся моделирование реакции речных бассейнов на внешние воздействия будет оставаться бесплодным, пока на основе широких полевых исследований не удастся уменьшить погрешность определений, по крайней мере пространственной изменчивости осадков и физических характеристик почв» [11. С. 15].

С этим мнением можно полностью согласиться, но рассчитывать на расширение полевых наблюдений в бассейнах сибирских рек не приходится. Метеорологическая сеть в период развала СССР подверглась значительному сокращению (или оптимизации). Можно лишь надеяться, что Национальные проекты России помогут восстановить утраченную часть сети Росгидромета [12, 13]. 


\section{Постановка задачи}

В первую очередь, максимальные уровни сибирских горных рек зависят от величины снегонакопления в бассейне. В то же время сложность механизмов снегонакопления и слабая обеспеченность гидрометеорологической информацией значительно затрудняют оценку снегозапасов. Традиционно в гидрологических исследованиях снегозапасы в горных районах увязывают с абсолютной высотой пунктов наблюдений $[14,15]$. В последние десятилетия разрабатываются гидрологические модели, основанные на данных дистанционного зондирования [3, 9, 10, 15-21].

Исследованию условий формирования талого стока бассейна р. Тубы и р. Амыл, в частности, посвящен ряд работ, выполненных на основе ландшафтногидрологического анализа и математического моделирования [22, 23], материалов снегомерных съемок и дистанционного зондирования [24]. В работах [8, 25] представлены модели множественной линейной регрессии для прогноза максимальных уровней воды и водности половодья.

В данной работе на примере бассейна р. Амыл разработаны статистические одно- и многофакторные модели среднесрочного прогноза объема стока и максимальных уровней половодья с использованием различных подходов к оценке сумм зимних осадков. Выполнен сравнительный анализ полученных моделей.

\section{Объект исследования}

Река Амыл является левым притоком р. Тубы (бассейн р. Енисей), впадающей в Красноярское водохранилище (рис. 1). Бассейн р. Амыл располагается в южной части Красноярского края, на северном склоне горной системы Западного Саяна.

Площадь бассейна р. Амыл в створе в/п Качулька (Качульские Выселки) составляет 9850 км², или примерно одну треть водосборного бассейна р. Тубы у в/п Бугуртак (31800 км²). Расстояние до впадения в p. Тубу - 11 км. Пост открыт в 1933 г. Основная площадь бассейна сосредоточена в высотном интервале от 250 до 1500 м, средняя высота водосбора - 797 м, максимальные отметки бассейна достигают 2200 м (вершина без названия, водораздел Амыла и Казыра). Абсолютные высоты водоразделов составляют 1500-2000 м. Большая часть водосборного бассейна залесена (94 \%), Заболоченность - 2 \% (в нижнем течении). На водораздельных участках выше 1,5 км имеются выходы скальных пород [26] (табл. 1).

Основным достоинством бассейна р. Амыл, с точки зрения гидрологических исследований, является обеспеченность метеорологическими наблюдениями (в частности, информацией об осадках) всей амплитуды высот бассейна (табл. 2).

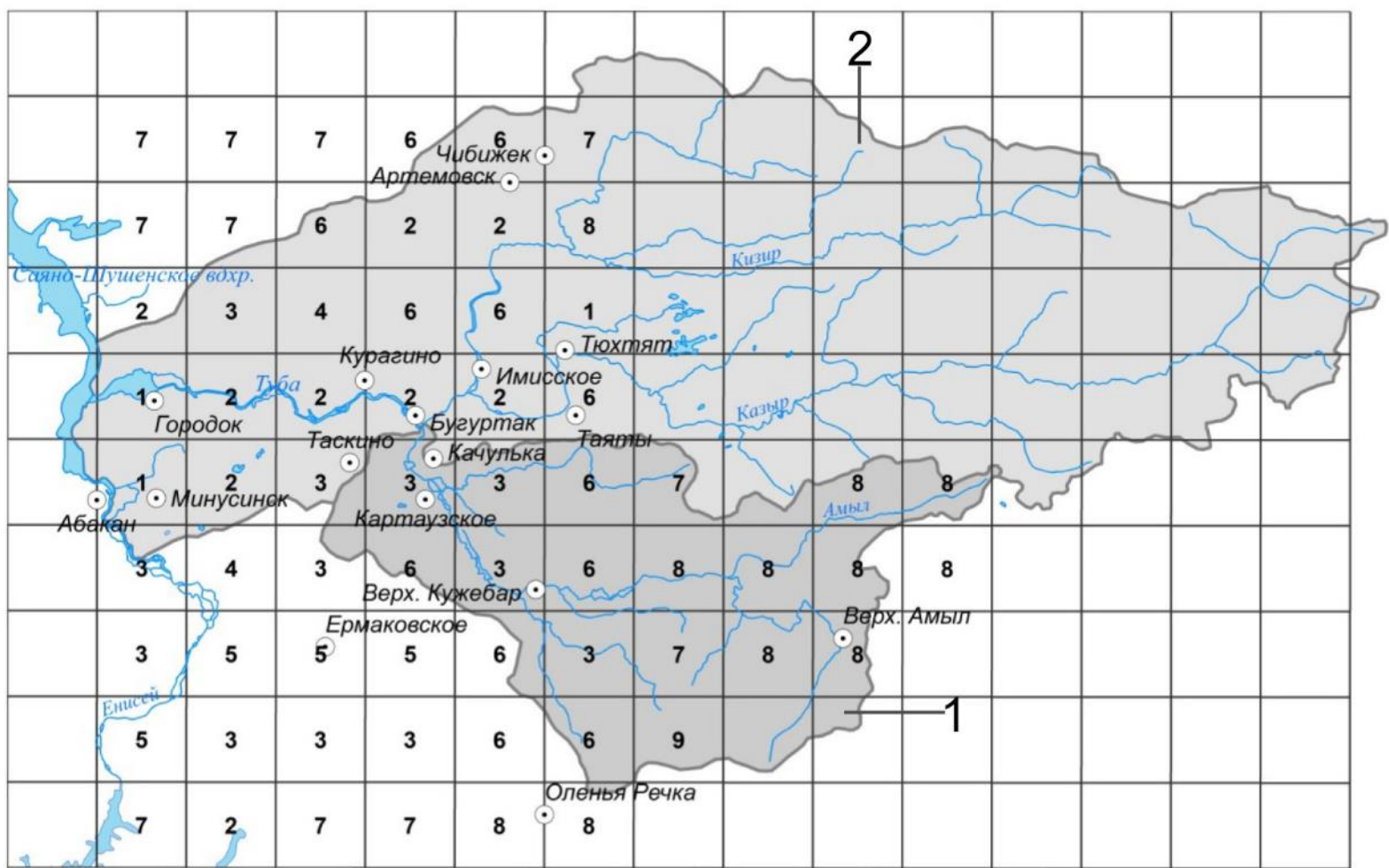

Pис. 1. Матрииа орографической добавки к скорости вертикальных движений для бассейна р. Амыл. Условные обозначения: 1) -0,75; 2) -0,27; 3) -0,055; 4)-0,025; 5) -0,0; 6) +0,055; 7) +0,3; 8) +0,75 м/с. Выделены бассейны: 1 - Амыла, 2 - Тубы. Орографическая добавка относится к левому нижнему углу ячейки

Fig. 1. Matrix of orographic correction to the velocity of vertical movements for the Amyl River basin. Symbols: 1) -0,75; 2) $-0,27$; 3) -0,055; 4) -0,025; 5) -0,0; 6) +0,055; 7) +0,3; 8) +0,75 m/s. The Amyl (1) and Tuba (2) basins are highlighted. The orographic correction refers to the low left corner of the cell 
Таблица 1. Абсолютная высота и сумма средних многолетних осадков за холодный период (ноябрь-март) в бассейне р. Амыл и нижней части бассейна р. Тубы [27]

Table 1. True altitude and average long-term precipitation amount for a cold period (NovemberMarch) in Amyl River and low Tuba River basins [27]

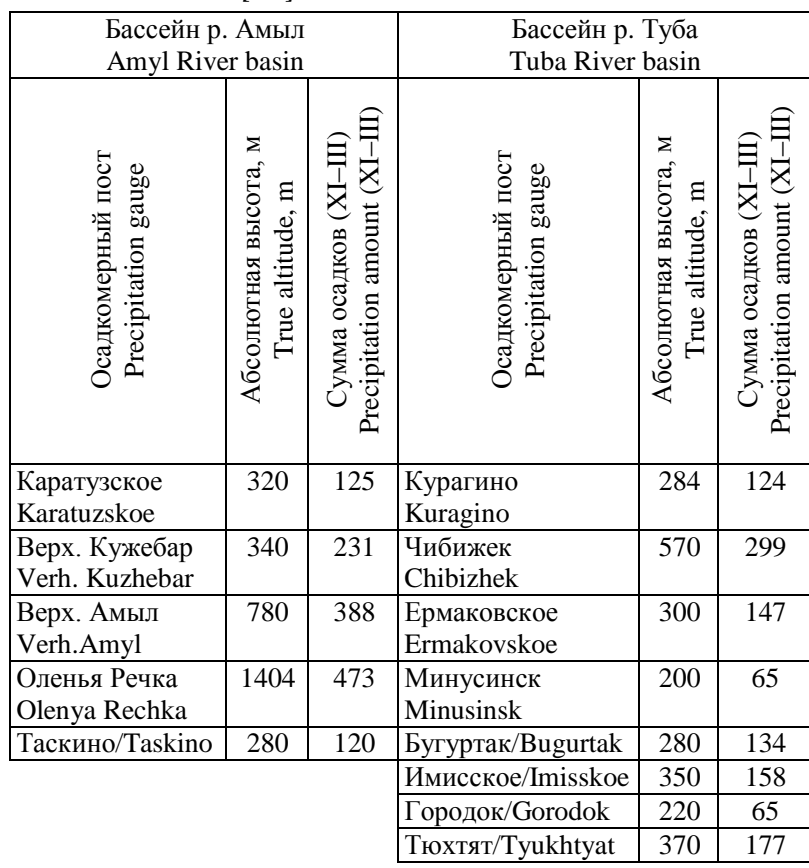

Таблица 2. Распределение по высотным зонам бассейна р. Амыл (до створа с. Качулька)

Table 2. Distribution of Amyl river basin (site Kachulka) by altitude zones

\begin{tabular}{|c|c|c|}
\hline $\begin{array}{c}\text { Высотная зона, м } \\
\text { Altitude zone, } \mathrm{m}\end{array}$ & $\begin{array}{c}\text { Площадь, км } \\
\text { Area, } \mathrm{km}^{2}\end{array}$ & $\begin{array}{c}\text { \% от всей площади } \\
\text { \% of total area }\end{array}$ \\
\hline $250-500$ & 3800 & 38,5 \\
\hline $500-1000$ & 3600 & 36,5 \\
\hline $1000-1500$ & 2100 & 21,4 \\
\hline$>1500$ & 350 & 3,6 \\
\hline всего/total & 9850 & 100 \\
\hline
\end{tabular}

\section{Исходные данные}

Для построения однофакторных моделей прогноза максимальных уровней и объема стока половодья выполнена оценка снегозапасов на основе метеорологических данных станций и постов, находящихся в пределах бассейна р. Амыл либо в непосредственной близости от него (табл. 1). Для оценки снегозапасов вычислялись суммы месячных осадков с октября предшествующего года по июнь (включительно) рассчитываемого. Кроме этого, по ГМС Верх. Кужебар (находится примерно в географическом центре исследуемого бассейна) использовались суточные данные о температуре воздуха и сумме осадков. Необходимые метеорологические данные выбирались из Метеорологических ежемесячников, публикация которых прекратилась в конце восьмидесятых годов прошлого века [28] (рис. 2, кривая 1).

Для проверки моделей выбран временной промежуток 2008-2017 гг. (выбор обусловлен наличием ис- ходных данных в открытых интернет-источниках). За этот период использовались данные метеорологических станций: Минусинск, Оленья Речка, Курагино, Щетинино (Чибижек). Привлекались также метеоданные бассейна р. Абакан: Неожиданный, Абакан, Шира, Коммунар, Таштып. Как показал сравнительный анализ зависимости орографической добавки к скорости вертикальных движений от абсолютной высоты пункта наблюдений, использование осадкомерных пунктов, расположенных в бассейне р. Абакан, вполне приемлемо (рис. 2, кривая 2).

Расчет сумм осадков выполнялся двумя способами: по высотным зависимостям (зависимость суммы осадков на метеостанции от ее абсолютной высоты) и по зависимостям от орографической добавки к скорости вертикальных движений (методика подробно описана в [29]).

Информация о максимальных уровнях и слое стока половодья по в/п Качулька за период 1966-1980 гг. взята из соответствующего справочника [30]. Для анализа половодья и выделения максимальных уровней за счет таяния снега за период 1981-1986 гг. [31] строились комплексные графики с суточным разрешением: ход уровней с марта по июль, термический режим и осадки по ГМС Верх. Кужебар.

Анализ гидрографа и оценка максимальных уровней за счет таяния снега за период 2008-2017 гг. выполнены аналогичным образом с использованием метеорологической информации по ГМС Каратузское, расположенной на левом берегу Амыла, в 15 км выше по течению в/п Качулька. Определение сроков половодья и расчет слоя стока за период 2008-2017 гг. проводились авторами также по комплексным графикам.

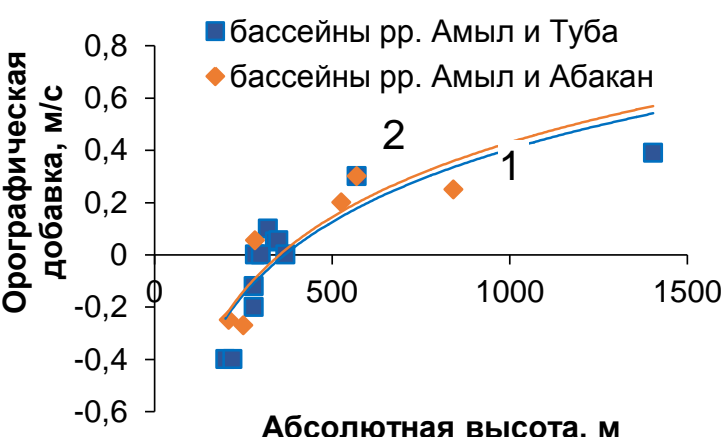

Pис. 2. Зависимости орографической добавки к скорости вертикальных движений от абсолютной высоты осадкомерных пунктов (1-y=0,41 $\ln (x)-2,41$, $R^{2}=0,8 ; 2-y=0,40 \ln (x)-2,38, R^{2}=0,74$, где $x-$ aбсолютная высота, $м ;$ - орографическая добав$\kappa a, \mu / c)$

Fig. 2. Dependences of orographic correction to the velocity of vertical movements on precipitation gauge altitudes $\left(1-y=0,41 \ln (x)-2,41, \quad R^{2}=0,8 ; \quad 2\right.$ $y=0,40 \ln (x)-2,38, R^{2}=0,74$, where $x$-absolute elevation, $m ; y$-orographic correction, $\mathrm{m} / \mathrm{s}$ )

Модель множественной линейной регрессии для прогноза максимальных уровней и объема половодья построена на основе анализа данных тех же метеостанций и постов (табл. 1). Дополнительно привлека- 
лись данные метеостанций, расположенных в направлении основных влагонесущих воздушных масс Абакан, Ненастная, Неожиданный. В качестве исходных данных использовались суммы месячных атмосферных осадков и среднемесячные температуры воздуха по перечисленным выше метеостанциям, а также максимальные запасы воды в снеге по метеостанциям Оленья Речка и Ермаковское.

\section{Результаты}

Как известно, сток половодья формируется под воздействием ряда факторов [1, 32-36], в число которых входят:

- запасы воды, накопленные в бассейне к началу снеготаяния;

- жидкие осадки в период снеготаяния и на спаде половодья;

- группа факторов, определяющих водопоглощающую емкость речного бассейна: состояние почвогрунтов, степень их увлажнения и промерзания.

Расчет суммы осадков за холодный период с использованием высотных зависимостей

Традиционно в гидрологических исследованиях величина снегозапасов в бассейне рассчитывается по высотным зависимостям [14]. Для бассейна р. Амыл прослеживается устойчивая статистически значимая $\left(\mathrm{R}^{2}=0,96\right)$ связь средней многолетней суммы осадков и абсолютной высоты, на которой установлен суммарный осадкомер (табл. 1, рис. 3).

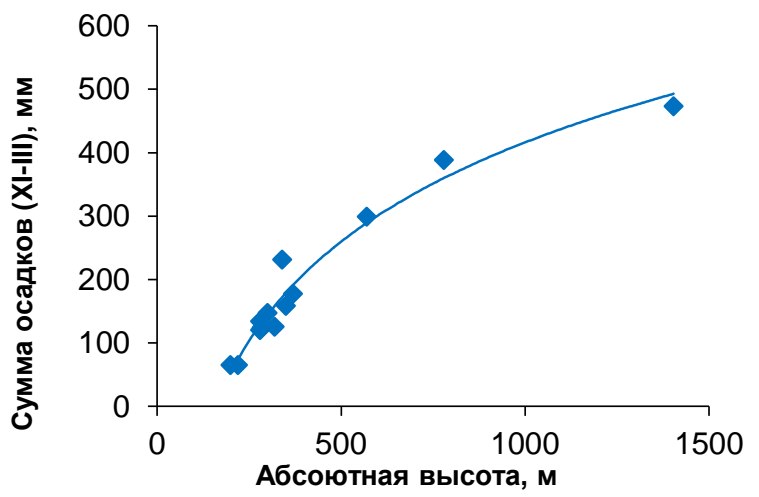

Pис. 3. Зависимость средней многолетней суммы осадков за холодный период (ноябрь-март) от абсолютной высоты осадкомерного поста (бассейн p. Амыл) $\left(y=225,7 \ln (x)-1142,9 ; R^{2}=0,96\right.$, где $x$ - абсолютная высота, м; $y$ - средняя многолетняя сумма осадков (ноябрь-март), мм)

Fig. 3. Dependence of average annual precipitation amount in the cold period (November-March) on precipitation gauge altitudes for the Amyl river basin $\left(y=225,7 \ln (x)-1142,9 ; R^{2}=0,96\right.$, where $x-$ absolute elevation, $m ; y$ - mean total precipitation (November-March), $\mathrm{mm}$ )

Расчет с использованием орографической добавки к скорости вертикальных движений

Для того чтобы предварительно оценить зависимость суммы зимних осадков от орографической добавки, построим аналогичный график связи средних многолетних сумм зимних осадков и величины орографической добавки к скорости вертикальных движений в пунктах наблюдения (табл. 3 , рис. 4).

Таблица 3. Орографическая добавка к скорости вертикальных движений и средняя многолетняя сумма зимних осадков (ноябрь-март) в бассейнах рек Амыл и Туба

Table 3. Orographic correction to the velocity of vertical movements and average long-term amount of winter precipitation (November-March) for Amyl and Tuba river basins

\begin{tabular}{|c|c|c|}
\hline $\begin{array}{c}\text { Осадкомерный } \\
\text { пункт } \\
\text { Precipitation gauge }\end{array}$ & $\begin{array}{c}\text { Орографическая } \\
\text { добавка, м/c } \\
\text { Orographic correc- } \\
\text { tion, m/s }\end{array}$ & $\begin{array}{c}\text { Сумма зимних } \\
\text { осадков, мм } \\
\text { Winter precipitation } \\
\text { amount, mm [27] }\end{array}$ \\
\hline Курагино/Kuragino & 0,055 & 124 \\
\hline Чибижек/Chibizhek & 0,3 & 299 \\
\hline $\begin{array}{l}\text { Каратузское } \\
\text { Karatuzskoe }\end{array}$ & 0,0 & 125 \\
\hline $\begin{array}{l}\text { Верх. Кужебар } \\
\text { Verh. Kuzhebar }\end{array}$ & 0,055 & 231 \\
\hline $\begin{array}{l}\text { Bерх. Амыл } \\
\text { Verh. Amyl }\end{array}$ & 0,55 & 388 \\
\hline $\begin{array}{l}\text { Оленья Речка } \\
\text { Olenya Rechka }\end{array}$ & 0,4 & 473 \\
\hline $\begin{array}{l}\text { Ермаковское } \\
\text { Ermakovskoe }\end{array}$ & 0,0 & 147 \\
\hline $\begin{array}{l}\text { Минусинск } \\
\text { Minusinsk }\end{array}$ & $-0,27$ & 65 \\
\hline Таскино/Taskino & $-0,27$ & 120 \\
\hline Бугуртак/Bugurtak & $-0,07$ & 134 \\
\hline Имисское/Imisskoe & 0,055 & 158 \\
\hline Городок/Gorodok & $-0,3$ & 65 \\
\hline Тюхтят/Tyukhtyat & 0,0 & 177 \\
\hline
\end{tabular}

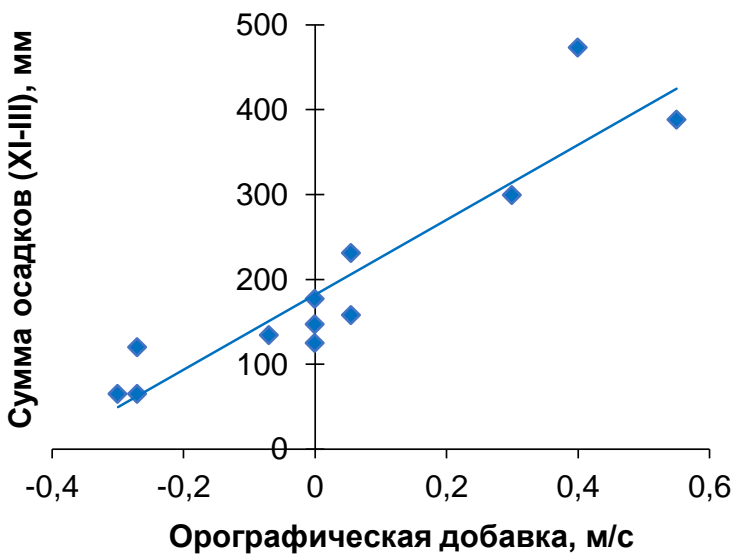

Pис. 4. Зависимость средней многолетней суммы осадков за холодный период (ноябрь-март) от орографической добавки к скорости вертикальных движений (бассейны рек Амыл $и$ Тубы) $\left(y=441,7 x-181,95 ; R^{2}=0,85\right.$, где $x$ - орографическая добавка, м/с; $у$ - сумма зимних осадков)

Fig. 4. Dependence of average annual precipitation amount in the cold period (November-March) on orographic correction to the velocity of vertical movements for Amyl and Tuba river basins $(y=441,7 x-$ 181,$95 ; R^{2}=0,85$, where $x$-orographic correction, $\mathrm{m} / \mathrm{s} ; y$-winter precipitation amount)

Как видим, также имеется сильная прямая линейная связь, но $\mathrm{R}^{2}$ (коэффициент детерминации) несколько меньше, чем для высотной зависимости (рис. 3). 
Для оценки ежегодной суммы зимних осадков в бассейне р. Амыл анализировались два периода: с зимы 1965-1966 гг. по 1985-1986 гг. и с зимы 2007-2008 гг. по 2016-2017 гг. Соответственно, расчет производился двумя способами - по высотной зависимости и по зависимости от орографической добавки к скорости вертикальных движений воздушных масс.

Сравнительный анализ расчетов средних для бассейна сумм зимних осадков по высотным зависимостям и по орографической добавке к скорости вертикальных движений показал, что эти суммы практически одинаковые (рис. 5).

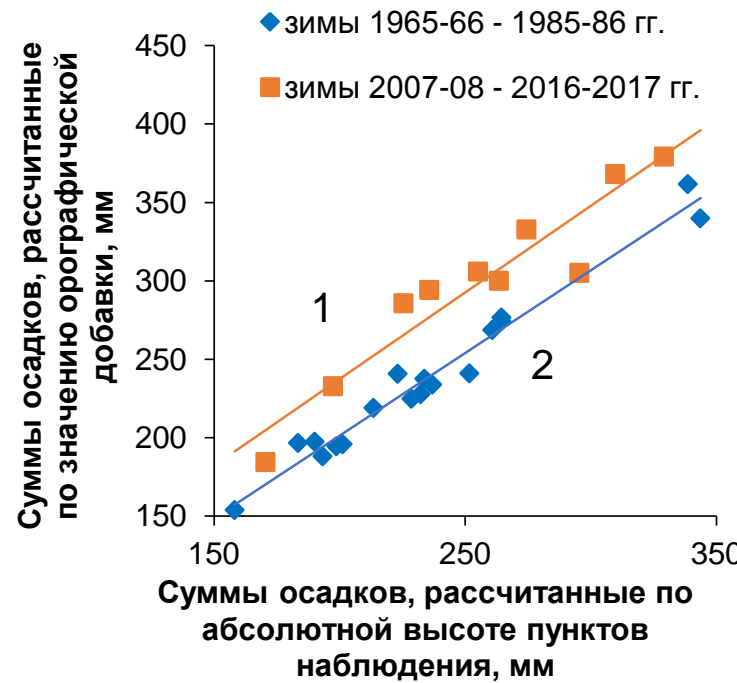

Рис. 5. Сравнительный анализ расчетов средних для бассейна сумм зимних осадков по высотным зависимостам и по орографической добавке к скорости вертикальных движений: $1-y=1,1 x+16,36 ; R^{2}=0,90$; $2-y=1,06 x-9,9 ; R^{2}=0,97$, где $x-$ суммы осадков, рассчитанные по абсолютной высоте пункта наблюдений; у - суммы осадков, рассчитанные по значению орографической добавки к скорости вертикальных движений

Fig. 5. Comparative analysis of average winter precipitation calculated for the basin by altitude dependencies and orographic correction to the velocity of vertical movements: $1-y=1,1 x+16,36 ; R^{2}=0,90$; $2-y=1,06 x-9,9 ; R^{2}=0,97$, where $x$ - precipitation amount calculated for the basin by altitude dependencies; $y$ - precipitation amount calculated for orographic correction to the velocity of vertical movements

Естественно, за счет использования различных осадкомерных пунктов наблюдается некоторое различие в результатах, особенно за период 2008-2017 гг., где практически половина осадкомерных пунктов взяты из бассейна р. Абакан. Но оно (различие), на наш взгляд, минимально. Таким образом, использование орографической добавки к скорости вертикальных движений дает те же самые результаты, что и традиционно используемые для расчетов высотные зависимости. Но высотные зависимости обеспечены, в подавляющем большинстве, лишь наблюдениями по долинам рек (т. е. части водосборного бассейна).
Бассейн р. Амыл - это единственный бассейн (в нашей практике), где на высоте 1,4 км есть метеорологическая станция Оленья Речка, т. е. практически вся амплитуда высот обеспечена данными наблюдений. Это дало возможность сравнить результаты расчетов по высотным зависимостям и по орографической добавке. Естественно, использование орографической добавки - это не универсальный прием, который решает все проблемы расчета ежегодных зимних осадков в условиях недостатка наблюдений. Например, в бассейне p. Чарыш низкогорная метеостанция Змеиногорск имеет очень большую орографическую добавку и тем самым обеспечивает всю амплитуду ее изменений в бассейне. Использование же высотных зависимостей в этом бассейне не приводит к положительным результатам [37].

\section{Влияние осадков на спаде половодья}

на максимальные уровни воды

Для оценки влияния жидких осадков на амплитуду уровней воды мы проанализировали динамику уровня воды в р. Амыл в период паводков, вызванных выпадением дождей на спаде половодья. Влияние дождей на динамику уровня воды до окончания снеготаяния оценить сложно, поэтому они, как правило, включаются в талый сток, т. к. имеют аналогичные условия стекания [38].

Для анализа дождевых паводков использованы годы с 1981 по 1984, по которым имеются уровни и данные метеостанции Верх. Кужебар (табл. 4).

Таблица 4. Время прохождения паводков и их подъем в бассейне р. Амыл (Качулька)

Table 4. Time of floods passage and their rise in the Amyl River basin (site Kachulka)

\begin{tabular}{|c|c|c|c|c|}
\hline $\begin{array}{c}\text { Год } \\
\text { Year }\end{array}$ & $\begin{array}{c}\text { Даты осад- } \\
\text { ков «одного» } \\
\begin{array}{c}\text { Dates of unit } \\
\text { rain precipita- } \\
\text { tion }\end{array}\end{array}$ & $\begin{array}{c}\text { Сумма осадков } \\
\text { (Верх. Кужебар), } \\
\text { мм } \\
\text { Precipitation } \\
\text { amount (Verh. Ku- } \\
\text { zhebar), mm }\end{array}$ & $\begin{array}{c}\text { Даты } \\
\text { подъема } \\
\text { уровня } \\
\text { Dates of } \\
\text { level rise }\end{array}$ & $\begin{array}{c}\text { Изменение } \\
\text { уровня, cм } \\
\text { Level } \\
\text { change, cm }\end{array}$ \\
\hline 1982 & $14-16.05$ & 59,3 & $17-19.05$ & 80 \\
\hline 1982 & $10-11.06$ & 15,4 & $10-12.06$ & 18 \\
\hline 1983 & $13-15.06$ & 16,3 & $14-16.06$ & 26 \\
\hline 1984 & $23-27.05$ & 28,9 & $27-30.05$ & 48 \\
\hline 1984 & $6-10.06$ & 43,0 & $7-12.06$ & 63 \\
\hline 1984 & $15-16.06$ & 13,9 & $15-17.06$ & 24 \\
\hline 1984 & $26-28.06$ & 35,8 & $27-30.06$ & 31 \\
\hline 1984 & $2-4.07$ & 28,7 & $3,4-5.07$ & 44 \\
\hline
\end{tabular}

Мы получили достаточно сильную зависимость подъёма уровней воды от суммы жидких осадков на ГМС Верх. Кужебар (рис. 6). Если использовать для аналогичной цели метеостанцию не в центре бассейна (например, Каратузское), то статистически значимая связь не наблюдается (рис. 7).

Таким образом, для включения в статистические модели осадков на спаде половодья необходимо выбирать ГМС примерно в географическом центре бассейна или характеризующую среднюю высоту водосборного бассейна. Метеостанция, находящаяся в районе выхода реки на предгорную равнину, не дает адекватных результатов 


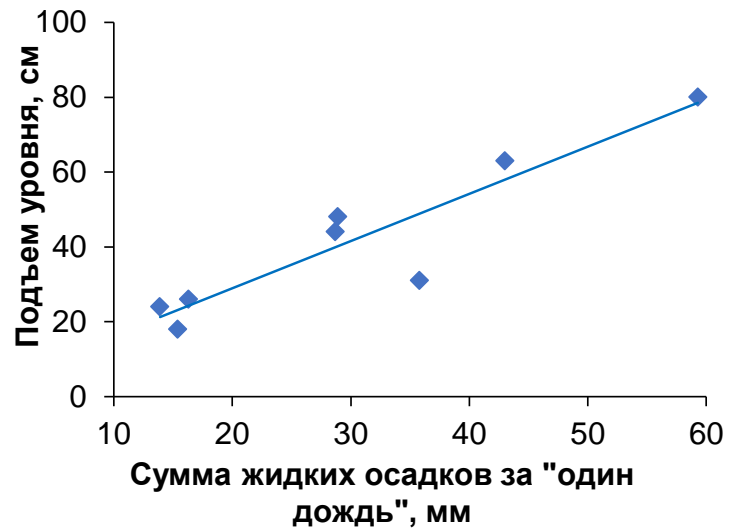

Pис. 6. Зависимость подъема уровня воды в створе АмылКачулька от суммы осадков за «один дождь» (период прохождения фронтальной зоны) по ГМС Верх. Кужебар ( $y=1,26 x+3,73 ; R^{2}=0,86$; где $x$ - сумма жидких осадков за «один дождь», - подъем уровня)

Fig. 6. Dependence of level rise in the Amyl-Kachulka site on a unit rain precipitation amount (the period of a frontal zone passage) according to the data from gauge Verh. Kuzhebar $\left(y=1,26 x+3,73 ; R^{2}=0,86\right.$, where $x$ precipitation amount of a unit rain; $y$-level rise)

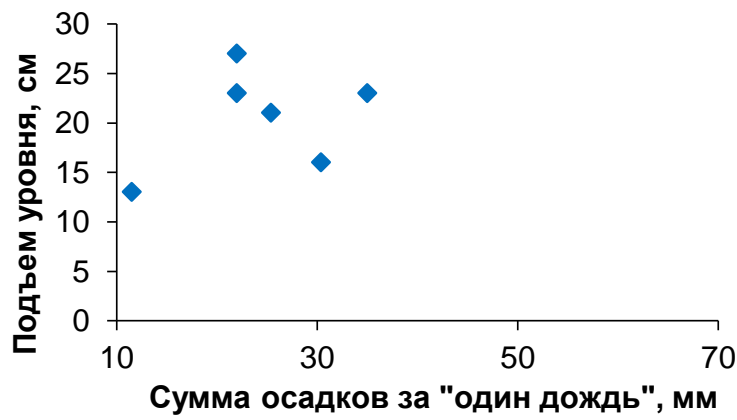

Рис. 7. Подъем уровня воды в створе Амыл-Качулька от суммы осадков за «один дождь» (период прохождения фронтальной зоны) по ГМС Каратузское

Fig. 7. Level rise in the Amyl-Kachulka site on a unit rain precipitation amount (the period of a frontal zone passage) according to the data from gauge Karatuzskoe

\section{Влияние промерзания почвогрунтов}

Влияние промерзания почвогрунтов в осенний период на сток половодья было рассмотрено нами достаточно подробно на примере бассейнов рр. Абакан, Ануй и Чарыш [37-40].

Материалы по бассейну р. Чарыша [37] и бассейну p. Абакан показали $[38,39]$, что условия осеннего промерзания влияют на максимальные уровни лишь в случае «присутствия» в бассейне значительной доли равнинных участков (в нашем случае это предгорные равнины). Если бассейн представлен лишь горным ландшафтом (бассейн р. Ануй [40], бассейн р. Амыл), то условия промерзания почвогрунтов слабо влияют на максимальные уровни и водность половодья
Однофракторные стохастические модели формирования максимальных уровней и слоя стока половодья

Для создания однофакторной модели формирования максимальных уровней воды и слоя стока половодья были проанализированы регрессионные зависимости характеристик половодья (максимальные уровни, слой стока) от суммы зимних осадков, рассчитанной при помощи высотных зависимостей и орографической добавки к скорости вертикальных движений.

Зависимость максимальных уровней воды в створе Амыл-Качулька за счет таяния снега от суммы зимних осадков представлена на рис. 8.

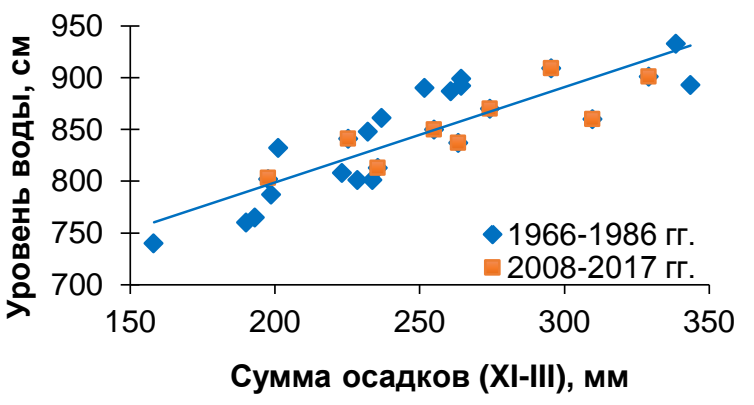

Pис. 8. Зависимость максимальных уровней воды, сформированных таянием снега, от суммы зимних осадков $\left(y=0,92 x+614,95 ; R^{2}=0,74\right.$, где $x$ - сумма зимних осадков; $y$ - максимальный средний суточный уровень)

Fig. 8. Dependence of snowmelt-induced maximum levels on winter precipitation amount $\left(y=0,92 x+614,95 ; R^{2}=0,74\right.$ where $x$-winter precipitation amount; $y$ - maximum mean daily level)

В построении зависимости не участвуют зимы 1971-1972, 1974-1975 и 2011-2012 гг., т. к. максимальные уровни сформированы и таянием снега, и жидкими осадками.

Попытаемся увязать полученную величину зимних осадков со слоем стока в створе Амыл-Качулька (рис. 9).

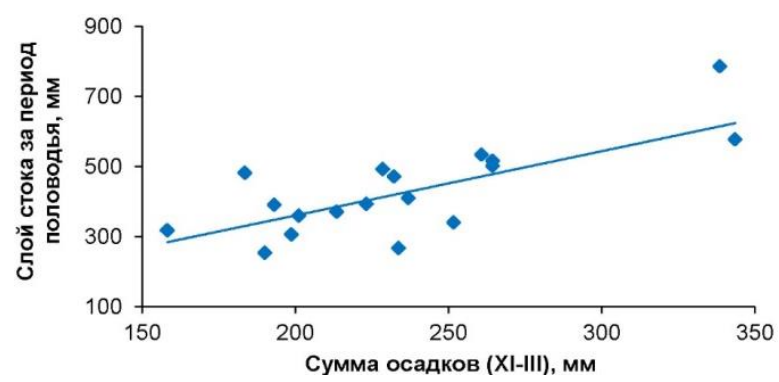

Pис. 9. Зависимость слоя стока половодья в створе АмылКачулька от суммы осадков за холодный период $\left(y=1,67 x^{1.014} ; R^{2}=0,49 ; x-\right.$ сумма зимних осадков; $y$-слой стока за период половодья)

Fig. 9. Dependence of flood runoff layer in the AmylKachulka site on precipitation amount in the cold pe$\operatorname{riod}\left(y=1,67 x^{1.014} ; R^{2}=0,49 ; x\right.$-winter precipitation amount; $y$ - runoff depth of snowmelt flood) 
Сток весеннего половодья зависит не только от суммы зимних осадков, но и от жидких осадков, выпадающих на спаде половодья (рис. 10). Как видим, разделение данных по продолжительности половодья (отдельно анализировались годы со значительным количеством осадков на спаде половодья) существенно увеличило коэффициент детерминации.

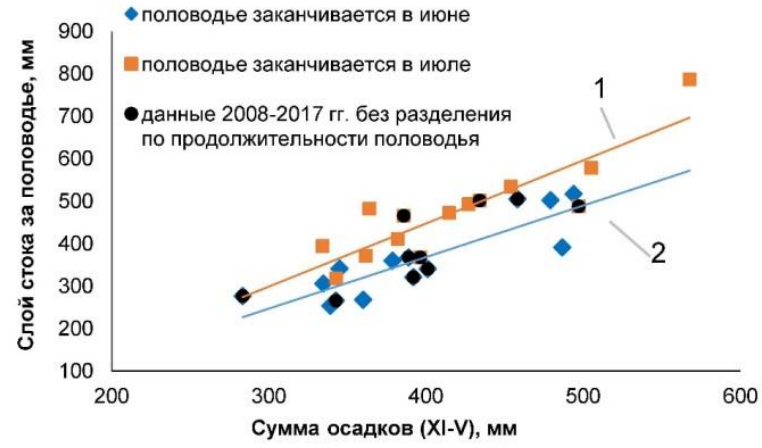

Puс. 10. Зависимость слоя стока половодья в створе Амыл-Качулька от суммы осадков за холодный период и осадков на спаде половодья (1 $y=1,49 x-147,02 ; \quad R^{2}=0,77 ; 2-y=1,21 x-117,15$; $R^{2}=0,76$, где $x$ - сумма осадков за ноябрь-май; $y$ - слой стока за период половодья)

Fig. 10. Dependence of runoff layer flood in the AmylKachulka site on precipitation amount in the cold period and during flood recession $(1-y=1,49 x-147,02$; $R^{2}=0,77 ; 2-y=1,21 x-117,15 ; R^{2}=0,76$, where $x-$ November-May precipitation amount; $y$ - runoff depth of snowmelt flood)

\section{Статистическая модель множественной регрессии}

На этапе отбора значимых предикторов построена и проанализирована корреляционная матрица, включающая следующие параметры:

1) среднемесячные температуры воздуха и суммы осадков с октября по июнь по всем метеостанциям и постам;

2) среднесезонные температуры воздуха и суммы осадков за зиму (IX-III)

3) средние температуры воздуха с начала половодья до окончания снеготаяния (IV-V)

4) суммы осадков за период половодья (IV-VI);

5) максимальные запасы воды в снеге по метеостанциям Ермаковское и Оленья Речка.

Выбор предикторов для построения уравнения осуществлялся путем пошаговой регрессии по мере уменьшения их влияния на сток. К сожалению, часть пунктов наблюдений имеет слишком короткий ряд (Верх. Кужебар, Таяты, Имисское, Богуртак, Каратуз ское), что не позволяет включить эти данные в уравнение регрессии.

Главным предиктором для прогноза объема стока и максимальных уровней половодья являются максимальные снегозапасы по ГМС Оленья Речка. На втором месте по значимости - сумма осадков за период с апреля по июнь: для максимальных уровней - по ГМС Ермаковское, а для объема половодья - по ГМС Оленья Речка. Связь снегозапасов и слоя стока свидетельствует о том, что основным источником полово- дья являются талые воды. Дождевые и смешанные осадки, выпавшие в период половодья и формирующие дождевые паводки, оказывают влияние на сток половодья в значительно меньшей степени.

Практически по всем метеостанциям наблюдается слабая отрицательная связь (коэффициент корреляции от 0,43 до 0,55 ) слоя стока и средней температуры воздуха в апреле-мае, т. е. с начала половодья до окончания снеготаяния в бассейне. Вероятно, это свидетельствует о влиянии испарения с поверхности бассейна на объем талых вод, поступающих в речную сеть. Однако включение данного предиктора в уравнение регрессии не улучшило качество модели.

В общем виде уравнение множественной линейной регрессии для слоя стока имеет вид:

$$
Y_{\text {половодья }}=26,23+0,41 X_{I V-V I}+0,41 S \text {; }
$$

для максимальных уровней:

$$
H_{\max }=713,5+0,26 X_{I V-V I}+0,18 S,
$$

где $Y_{\text {половодья }}$ - слой стока периода половодья, мм; $X_{I V-}$ $V I$ - осадки за апрель-май по соответствующей ГМС (для $Y_{\text {половодья }}$ - Оленья Речка, для $H_{\max }-$ Ермаковское); $S$ - максимальные снегозапасы по ГМС Оленья Речка.

Параметры качества уравнений множественной регрессии представлены в табл. 5.

Таблица 5. Параметры уравнения множественной регрессии для прогнозирования слоя стока $и$ максимальных уровней половодья

Table 5. Parameters of a multiple regression equation for predicting runoff layer and maximum flood levels

\begin{tabular}{|l|c|c|}
\hline \multicolumn{1}{|c|}{$\begin{array}{c}\text { Итоговые статистики } \\
\text { Summary statistics }\end{array}$} & $\begin{array}{c}\text { Модель 1: } \\
\mathrm{Y}_{\text {половодья }} \\
\text { Model 1: } \mathrm{Y}_{\text {flood }}\end{array}$ & $\begin{array}{c}\text { Модель } \\
\text { 2: } \mathrm{H}_{\max } \\
\text { Model 2: } \mathrm{H}_{\max }\end{array}$ \\
\hline $\begin{array}{l}\text { Множественный R } \\
\text { Multiple R }\end{array}$ & 0,85 & 0,73 \\
\hline $\mathrm{R}^{2}$ & 0,72 & 0,54 \\
\hline $\begin{array}{l}\text { Нормированный } \mathrm{R}^{2} \\
\text { Adjusted R }\end{array}$ & 0,7 & 0,5 \\
\hline $\begin{array}{l}\text { Стандартная ошибка } \\
\text { Standard error }\end{array}$ & 50,43 & 32,68 \\
\hline $\mathrm{F}$ & 33,02 & 14,98 \\
\hline Наблюдения/Observations & 29 & 29 \\
\hline
\end{tabular}

Сравнительный анализ результатов моделирования

На заключительном этапе выполнен сравнительный анализ моделей множественной линейной регрессии и однофакторных моделей. Метод множественной линейной регрессии для прогноза максимальных уровней р. Амыл показал результат хуже $\left(\mathrm{R}^{2}=0,54\right)$, чем однофакторная зависимость от сумм зимних осадков, рассчитанных с помощью высотных зависимостей и орографической добавки $\left(\mathrm{R}^{2}=0,74\right)$.

Для прогноза слоя стока, напротив, модель множественной регрессии более предпочтительна $\left(\mathrm{R}^{2}=0,71\right)$, чем однофакторные регрессии, построенные без учета осадков на спаде половодья и продолжительности половодья $\left(\mathrm{R}^{2}=0,49\right)$. При учете осадков на спаде половодья модель множественной регрессии и традиционный метод на основе высотных зависимостей или орографической добавки имеют примерно одинаковую тесноту связи. 


\section{Выводы}

1. Расчет сумм зимних осадков в бассейне р. Амыл по традиционно применяемой в гидрологии зависимости от высоты и с помощью орографической добавки к скорости вертикальных движений показал идентичные результаты.

2. Сравнительный анализ методик прогноза максимальных уровней воды показал, что однофакторные зависимости имеют более высокие коэффи-

\section{СПИСОК ЛИТЕРАТУРЫ}

1. Аполлов Б.А., Калинин Г.П., Комаров В.Д. Курс гидрологических прогнозов. - Л.: Гидрометеоиздат, 1974. - 422 с.

2. Владимиров А.М. Факторы, определяющие возникновение экстремальных расходов и уровней воды половодья // Ученые записки Российского государственного гидрометеорологического университета. - 2009. - № 9. - С. 22-39.

3. Streamflow response to seasonal snow cover mass changes over large Siberian watersheds / D. Yang, Y. Zhao, R. Armstrong, D. Robinson, M.J. Brodzik // Journal of Geophysical Research: Earth Surface. - 2007. - V. 112. - № 2. - P. F02S22.

4. Gelfan A.N. Extreme snowmelt floods: frequency assessment and analysis of genesis on the basis of the dynamic-stochastic approach // Journal of Hydrology. - 2010. - V. 388. - № 1-2. P. 85-99.

5. DeWalle D.R., Rango A. Principles of Snow Hydrology. Cambridge: Cambridge University Press, 2008. -428 p.

6. Hydrologic Modeling System (HEC-HMS) user guide: Version 4.2 Institute for Water Resources, Hydrologic Engineering Center, Davis, CA. U.S. Army Corps of Engineers. - 2016. URL: https://www.hec.usace.army.mil/software/hec-

hms/documentation/HEC-HMS_Users_Manual_4.2.pdf (дата обращения 15.03.2020)

7. Снежно-водно-ледниковые ресурсы бассейна Верхней Оби и прогнозы стока весеннего половодья / под ред. Д.А. Буракова. Томск: Изд-во ТГУ, 1986. - 254 с.

8. Паромов В.В., Шумилова К.А., Гордеев И.Н. Условия формирования половодья большой водности и прогноз наводнения на реке Абакан // Известия Томского политехнического университета. Инжиниринг георесурсов. - 2016. - Т. 327. № 11. - C. 57-67.

9. Advances in snow hydrology using a combined approach of GNSS in situ stations, hydrological modelling and Earth observation - a case study in Canada / F. Appel, F. Koch, A. Rösel, P. Klug, P. Henkel, M. Lamm, W. Mauser, H. Bach // Geosciences. 2019. - V. 9 (1):44. URL: https://doi.org/10.3390/geosciences9010044 (дата обращения 15.03.2020)

10. Using MODIS estimates of fractional snow cover area to improve streamflow forecasts in interior Alaska / K.E. Bennett, J.E. Cherry, S. Lindsey, B. Balk // Hydrology and Earth System Sciences. 2019. - V. 23. - № 5. - P. 2439-2459.

11. Грани гидрологии / под ред. Д.К. Родда. - Л.: Гидрометеоиздат, 1987. $-536 \mathrm{c}$.

12. Перспективы совершенствования технологии экологического мониторинга поверхностных вод Обь-Иртышского бассейна / Д.М. Безматерных, А.В. Пузанов, Т.С. Папина, В.В. Кириллов, И.Д. Рыбкина, О.В. Ловцкая, Я.Э. Кузняк // Известия Алтайского отделения русского географического общества. 2020. - Т. 57. - № 2. -C. 49-58.

13. Федеральный проект «Цифровой Обь-Иртышский бассейн» URL: https://nticenter.spbstu.ru/nti_projects/43 (дата обращения 15.06.2021).

14. Ревякин В.С., Кравцова В.И. Снежный покров и лавины Алтая. - Томск: Изд-во Томского университета, 1977. - 216 с.

15. Сезонные закономерности распределения осадков на территории Западного Саяна и их учет при моделировании стока Г.В. Пряхина, Е.С. Зелепукина, Т.Н. Осипова, С.А. Гаврилкина, В.А. Соловьев, Т.А. Виноградова // Вестник Санкт-Петербургского университета. Науки о Земле. - 2019. T. 64. - № 3. - C. 466-476. циенты детерминации, чем модель множественной регрессии.

3. Для прогноза слоя стока, чтобы получить значимый результат, необходимо учитывать осадки на спаде половодья. В этом случае однофакторные модели и модель множественной регрессии показывают примерно идентичные результаты.

Работа выполнена в рамках государственного задания Института водных и экологических проблем Сибирского отделения Российской академии наук (ИВЭП СО РАН).

16. Snow cover mapping for complex mountainous forested environments based on a multi-index technique / X. Wang, J. Wang, T. Che, X. Huang, X. Hao, H. Li // IEEE Journal of Selected Topics in Applied Earth Observations and Remote Sensing. - 2018. - V. 11. - № 5. - P. 1433-1441. URL: https://doi.org/10.1109/JSTARS.2018.2810094 (дата обращения 15.03.2020).

17. Gampe D., Ludwig R. Evaluation of gridded precipitation data products for hydrological applications in complex topography // Hydrology. - 2017. - V. 4 (4):53. URL: https://doi.org/ 10.3390/hydrology4040053 (дата обращения 15.06.2021).

18. Evaluation of multi-satellite precipitation datasets and their error propagation in hydrological modeling in a monsoon-prone region / J. Chen, Z. Li, L. Li, J. Wang, W. Qi, C-Y. Xu, J-S. Kim // Remote Sensing. - 2020. - V. 12 (21):3550. URL: https://doi.org/10.3390/rs12213550 (дата обращения 15.06.2021).

19. Ромасько В.Ю., Бураков Д.А. Космический мониторинг заснеженности территории речных бассейнов // Журнал Сибирского федерального университета. Серия: Техника и технологии. - 2017. - Т. 10. - № 6. - С. 704-713.

20. Marcil G.-K., Trudel M., Leconte R. Using remotely sensed MODIS snow product for the management of reservoirs in a mountainous canadian watershed // Water Resources Management. 2016. - V. 30 (8). - P. 2735-2747.

21. Şorman A.A., Uysal G., Şensoy A. Probabilistic snow cover and ensemble streamflow estimations in the Upper Euphrates Basin // Journal of Hydrology and Hydromechanics. - 2019. - V. 67. № 1. - Р. 82-92.

22. Ландшафтно-гидрологическая структура водосбора р. Амыл Г.В. Пряхина, Е.С. Зелепукина, С.А. Журавлев, Н.И. Амбурцева, К.В. Чистяков // География и природные ресурсы. - 2014. № 4. - C. 131-137.

23. Пространственная структура формирования стока на основе математического моделирования / Г.В. Пряхина, Е.С. Зелепукина, С.А. Гаврилкина, В.А. Соловьев, Н.И. Амбурцева, Т.А. Виноградова // Известия академии наук. Серия географическая. - 2020. - Т. 84. - № 2. -С. 218-227.

24. Бураков Д.А., Гордеев И.Н. Оценка предвесенних снегозапасов в бассейнах Красноярского и Саяно-Шушенского водохранилищ // География и природные ресурсы. - 2013. - № 1. - С. 72-78.

25. Бураков Д.А., Космакова В.Ф., Гордеев И.Н. О результатах испытания методов прогноза максимальных уровней воды весеннего половодья р. Туба у пос. Курагино и р. Подкаменная Тунгуска у с. Ванавара // Результаты испытания новых и усовершенствованных технологий, моделей и методов гидрометеорологических прогнозов. - 2014. - № 41. - С. 89-97.

26. Ресурсы поверхностных вод СССР. Т. 16. Ангаро-Енисейский район. Вып. 1. Енисей / под ред. А.П. Муранова. - Л.: Гидрометеоиздат, 1973. - 724 с.

27. Справочник по климату СССР. Вып. 21. Влажность воздуха, атмосферные осадки, снежный покров. - Л.: Гидрометеоиздат, 1969. $-405 \mathrm{c}$

28. Метеорологический ежемесячник. Ч. 2. Вып. 21. Краснояр. террит. упр. по гидрометеорологии и контролю природ. среды. - Красноярск: Красноярская гидрометеорол. обсерватория, 1966-1987.

29. Галахов В.П. Условия формирования и расчет максимальных снегозапасов в горах. - Новосибирск: Наука, 2003. - 104 с.

30. Характерные уровни воды рек, каналов и водохранилищ (погодичные данные). Т. 1. Вып. 12. Бассейн Енисея (без бассейна Ангары) и Пясины. - Л.: Гидрометеоиздат, 1989, 108 с. 
31. Ежегодные данные о режиме и ресурсах поверхностных вод суши: Ч. 1. Реки и каналы. Т. 1: Вып. 12. Бассейны Енисея (без бассейна Ангары) и Пясины. - Л.: Гидрометеоиздат, 1966-1987.

32. Effects of preferential flow on snowmelt partitioning and groundwater recharge in frozen soils / A.A. Mohammed, I. Pavlovskii, E.E. Cey, M. Hayashi // Hydrology and Earth System Science. - 2019. - V. 23. - P. 5017-5031. URL https://doi.org/10.5194/hess-23-5017-2019 (дата обращения 13.12.2020)

33. Effects of snow coveron soil freezing, water movement, and snowmelt infiltration: a pairedplot experiment / Y. Iwata, M. Hayashi, S. Suzuki, T. Hirota, S. Hasegawa // Water resources research. - 2010. - V. 46. - № 9. - Article number W09504. URL: https://doi.org/10.1029/2009WR008070 (дата обращения 13.12.2020).

34. Effects of soil water and heat relationship under various snow cover during freezing-thawing periods in Songnen Plain, China / Q.Fu, R. Hou, T. Li, R. Jiang, P. Yan, Z. Ma, Z.Zhou // Scientific Reports. - 2018. - V. 8. - № 1. - Article number 1325. URL: https://doi.org/10.1038/s41598-018-19467-у (дата обращения 13.12.2020)

35. Effect of snowmelt infiltration on groundwater recharge in a seasonal soil frost area: a case studyin Northeast China / X. Du, M Fang, H. Lv, T. Cheng, P. Hong, C. Liu // Environmental Monitoring and Assessment. - 2019. - V. 191. - Article Number 151. - P. 1-11. URL: https://doi.org/10.1007/s10661-0197285-7 (дата обращения 13.12.2020).
36. Silvestro F., Rebora N. Impact of precipitation forecast uncertainties and initial soil moisture conditions on a probabilistic flood forecasting chain // Journal of Hydrology. - November 2014. - V. 519. - P. 1052-1067.

37. Влияние осеннего промерзания на максимальные уровни бассейна реки Чарыш / В.П. Галахов, Е.В. Мардасова, Н.В. Люцигер, С.Ю. Самойлова // Известия Алтайского отделения русского географического общества. - 2018. - Т. 48. - № 1. C. 54-57.

38. Бураков Д.А., Иванова О.И. Анализ формирования и прогноз стока весеннего половодья в лесных и лесостепных бассейнах рек Сибири // Метеорология и гидрология. - 2010. - № 6. C. $87-110$.

39. Галахов В.П., Ловцкая О.В., Мардасова Е.В. Влияние климатических изменений на максимальные уровни периода половодья реки Абакан // Известия Томского политехнического университета. Инжиниринг георесурсов. - 2021. - Т. 332. № 3. - C. 219-228.

40. Галахов В.П., Самойлова С.Ю., Мардасова Е.В. Влияние условий формирования снежного покрова на сток половодья горной реки (на примере бассейна реки Ануй) // Известия Алтайского отделения русского географического общества. 2020. - T. 56. - № 1. - C. 24-33.

Поступила 02.02.2022 г.

\section{Информация об авторах}

Галахов В.П., кандидат географических наук, старший научный сотрудник Института водных и экологических проблем СО РАН.

Ловцкая O.B., старший научный сотрудник Института водных и экологических проблем СО РАН.

Самойлова С.Ю., кандидат географических наук, научный сотрудник Института водных и экологических проблем СО РАН.

Mapдасова E.B., старший преподаватель кафедры экономической географии и картографии, Институт географии Алтайского государственного университета. 
UDC556.161:556.166

\title{
COMPARATIVE ANALYSIS OF METHODS FOR FORECASTING MAXIMUM LEVELS AND VOLUMES OF FLOOD RUNOFF OF A MOUNTAIN RIVER
}

\author{
Vladimir P. Galakhov' \\ galahov@iwep.ru
}

Olga V. Lovtskaya1, lov@iwep.ru

\author{
Svetlana Yu. Samoilova ${ }^{1}$, \\ bastet05@list.ru \\ Elena V. Mardasova² \\ mardasovaev@mail.ru \\ 1 Institute for Water and Environmental Problems SB RAS, \\ 1, Molodezhnaya street, Barnaul, 656038, Russia \\ 2 Altai State University, \\ 61, Lenin avenue, Barnaul, 656049, Russia.
}

The study topicality relates to the analysis of available methods for assessing snow reserves in river basins and forecasting floods. To predict runoff volume and maximum flood levels, statistical models resting on the correlation dependence of runoff parameters on snow reserves or multiple linear regression equations are usually used in the absence of sufficient hydrometeorological information. An important point is that there are no justified comparisons of traditional forecasting methods based on calculations of winter precipitation amount (snow reserves) and statistical models of multiple regression.

The aim of the study is to carry out the comparative analysis of methods for calculating winter precipitation amounts in the basin by means of traditionally applied altitude dependencies and the author's estimation method using orographic correction to the velocity of vertical movements of air masses; to carry out the comparative analysis of traditional statistical forecasting methods and models of multiple linear regression by the example of the Amyl River basin.

Methods: comprehensive geographical and hydrometeorological analysis; dependence establishment based on long-term hydrometeorological observations using methods of mathematical statistics (correlation and regression analysis); snow reserves simulation with the use of orographic correction to the velocity of vertical movements.

Results. By altitude dependencies and the author's assessment considering orographic correction to the velocity of vertical movements of air masses, two different approaches to estimate of winter precipitation amounts suggest similar statistical dependences with close values of determination coefficients. Models for predicting runoff volumes and maximum flood stages based on pair correlation and multiple regression analysis were developed. The comparative analysis of traditional methods for forecasting runoff layers based on calculations of winter precipitation amount (snow reserves) and statistical models of multiple regression also showed similar results. The applied onefactor dependencies turned out to be the best in forecasting snowmelt-induced maximum levels.

\section{Key words:}

Zapadny Sayan, Tuba River, Amyl River basin, winter precipitation, snow reserves, altitude dependence, orographic correction to the velocity of vertical movements, statistical model of multiple regression.

The research was carried out within the State Task of the Institute for Water and Environmental Problems SB RAS.

\section{REFERENCES}

1. Apollov B.A., Kalinin G.P., Komarov V.D. Kurs gidrologicheskikh prognozov [A course of hydrological forecasts]. Leningrad, Gidrometeoizdat Publ., 1974. 422 p.

2. Vladimirov A.M. Faktory, opredelyayushchie vozniknovenie ekstremalnykh raskhodov i urovney vody polovodya [Factors initiating occurrence of extreme flow rates and flood water levels]. Proceedings of the Russian State Hydrometeorological University, 2009, no. 9, pp. 22-39.

3. Yang D., Zhao Y., Armstrong R., Robinson D., Brodzik M.J. Streamflow response to seasonal snow cover mass changes over large Siberian watersheds. Journal of Geophysical Research: Earth Surface, 2009, vol. 112, no. 2, p. F02S22

4. Gelfan A.N. Extreme snowmelt floods: frequency assessment and analysis of genesis on the basis of the dynamic-stochastic approach. Journal of Hydrology, 2010, vol. 388, no. 1-2, p. 85-99.

5. DeWalle D.R., Rango A. Principles of Snow Hydrology. Cambridge, Cambridge University Press, 2008. 428 p.

6. Hydrologic Modeling System (HEC-HMS) user guide: Version 4.2 Institute for Water Resources, Hydrologic Engineering Center,
Davis, CA. U.S. Army Corps of Engineers, 2016. Available at: www.hec.usace. army.milshec-hms $\mathrm{HEC}$ -

HMS_Users_Manual_4.2.pdf (accessed: 15 March 2020).

7. Snezhno-vodno-lednikovye resursy basseyna Verkhney Obi $i$ prognozy stoka vesennego polovodya [Snow-water-glacial resources of the Upper $\mathrm{Ob}$ basin and forecasts of spring flood runoff]. Ed. by D.A. Burakov. Tomsk, TSU Publ. House, 1986. 254 p.

8. Paromov V.V., Shumilova K.A., Gordeev I.N. Conditions of formation of high-water flood and flood forecast on the river Abakan. Bulletin of the Tomsk Polytechnic University. Geo Assets Engineering, 2016, vol. 327, no. 11. pp. 57-67. In Rus.

9. Appel F., Koch F., Rösel A., Klug P., Henkel P., Lamm M., Mauser W., Bach H. Advances in snow hydrology using a combined approach of GNSS in situ stations, hydrological modelling and earth observation - a case study in Canada. Geosciences, 2019, vol. 9 (1):44. Available at: https://doi.org/10.3390/geosciences 9010044 (accessed: 15 March 2020).

10. Bennett K.E., Cherry J.E., Lindsey S., Balk B. Using MODIS estimates of fractional snow cover area to improve streamflow forecasts in interior Alaska. Hydrology and Earth System Sciences, 2019, vol. 23 , no. 5, pp. 2439-2459. 
11. Grani gidrologii [Facets of hydrology]. Ed. by Rodda J.C. Leningrad, Gidrometeoizdat Publ., 1987. 536 p.

12. Bezmaternykh D.M., Puzanov A.V., Papina T.S., Kirillov V.V., Rybkina I.D., Lovtskaya O.V., Kuznyak Ya.E. Prospects for improving the technology of environmental monitoring of surface waters in the Ob-Irtysh basin. Bulletin of the Altay branch of the Russian geographical society, 2020, vol. 57, no. 2, pp. 49-58. In Rus.

13. Federalny proekt «tsifrovoy Ob-Irtyshsky Basseyn» [Federal project «Digital Ob-Irtysh basin»]. 2020. Available at: https://nticenter.spbstu.ru/nti_projects/43 (accessed: 15 June 2021)

14. Revyakin V.S., Kravtsova V.I. Snezhny pokrov i laviny Altaya [Snow cover and avalanches of Altai]. Tomsk, Tomsk University Publ. House, 1977. $216 \mathrm{p}$

15. Pryakhina G.V., Zelepukina E.S., Osipova T.N., Gavrilkina S.A., Solovyev V.A., Vinogradova T.A. Seasonal distribution patterns of precipitation on the territory of West Sayan Ridge and their consideration in runoff modeling. Vestnik of St Petersburg Univer sity. EarthSciences, 2019, vol. 64, no. 3, pp. 466-476. In Rus.

16. Wang X., Wang J., Che T., Huang X., Hao X., Li H. Snow cover mapping for complex mountainous forested environments based on a multi-index technique. IEEE Journal of Selected Topics in Applied Earth Observations and Remote Sensing, 2018, vol. 11 no. 5, pp. 1433-1441. Available at: https://doi.org/10.1109/ JSTARS.2018.2810094 (accessed: 15 June 2021).

17. Gampe D., Ludwig R. Evaluation of gridded precipitation data products for hydrological applications in complex topography Hydrology, 2017, vol. 4 (4):53. Available at: https://doi.org/ 10.3390/hydrology4040053 (accessed: 15 June 2021).

18. Chen J., Li Z., Li L., Wang J., Qi W., Xu C-Y., Kim J-S. Evaluation of multi-satellite precipitation datasets and their error propagation in hydrological modeling in a Monsoon-Prone Region. Remote Sensing, 2020, vol. 12 (21):3550. Available at: https://doi.org/10.3390/rs12213550 (accessed: 15 June 2021).

19. Romasko V.Y., Burakov D.A. Space monitoring of snow cover of river watersheds. Journal of Siberian Federal University. Engineering \& Technologies, 2017, vol. 10 (6), pp. 704-713.

20. Marcil G.-K., Trudel M., Leconte R. Using remotely sensed MODIS snow product for the management of reservoirs in a mountainous Canadian Watershed. Water Resources Management, 2016, vol. 30 (8), pp. 2735-2747.

21. Şorman A.A., Uysal G., Şensoy A. Probabilistic snow cover and ensemble streamflow estimations in the Upper Euphrates Basin. Journal of Hydrology and Hydromechanics, 2019, vol. 67, no. 1. pp. 82-92.

22. Pryakhina G.V., Zelepukina E.S., Zhuravlev S.A., Amburtseva N.I., Chistyakov K.V. Landshaftno-gidrologicheskaya struktura vodosbora $r$. Amyl [A landscape-hydrological structure of the Amyl catchment]. Geography and natural resources, 2014, no. 4, pp. 131-137.

23. Pryakhina G.V., Zelepukina E.S., Gavrilkina S.A., Solovyev V.A., Amburtseva N.I., Vinogradova T.A. Mathematical modeling of runoff formation spatial structure. Izvestiya Rossiiskoi Akademii Nauk. Seriya Geograficheskaya, 2020, vol. 84, no. 2, pp. 218-227. In Rus.

24. Burakov D.A., Gordeev I.N. Otsenka predvesennikh snegozapasov v basseynakh Krasnoyarskogo i Sayano-Shushenskogo vodokhranilishch [Assessment of pre-spring snow reserves in the basins of Krasnoyarsk and Sayano-Shushensk reservoirs]. Geography and natural resources, 2013, no. 1, pp. 72-78.

25. Burakov D.A., Kosmakova V.F., Gordeev I.N. O rezultatakh ispytaniya metodov prognoza maksimalnykh urovney vody vesennego polovodya r. Tuba u pos. Kuragino i r. Podkamennaya Tunguska u s. Vanavara [Test results of methods for predicting maximum water levels of spring flood on R.Tuba at Kuragino and R. Podkamennaya Tunguska at Vanavara]. Test results of new and upgraded technologies, models and methods for hydrometeorolog ical forecasts, 2014, no. 41, pp. 89-97.

26. Resursy poverkhnostnykh vod SSSR. T. 16. Vyp. 1. AngaroYeniseyskiy rayon. Yenisey [Surface water resources in the USSR
Vol. 16. Iss. 1. Angara-Yenisey region. Yenisey]. Ed. by A.P. Muranov. Leningrad, Gidrometeoizdat Publ., 1973. 724 p.

27. Spravochnik po klimatu SSSR. Vyp. 21. Vlazhnost vozdukha, atmosfernye osadki, snezhny pokrov [Handbook on climate of the USSR. Iss. 21. Air humidity, precipitation, snow cover]. Leningrad, Gidrometeoizdat Publ., 1969. 405 p.

28. Meteorologicheskiy ezhemesyachnik [Meteorological Monthly]. P. 2, Iss. 21. Krasnoyarsk, 1966-1987.

29. Galakhov V.P. Usloviya formirovaniya i raschet maksimalnykh snegozapasov $v$ gorakh [Conditions for formation and estimationof maximum snow storage in mountains]. Novosibirsk, Nauka Publ., 2003. $104 \mathrm{p}$.

30. Kharakternye urovni vody rek, kanalov, ozer $i$ vodokhranilishch (pogodichnye dannye). Ch. 1. Reki i kanaly. Vyp. 12. Basseyny Yeniseya (bez basseyna Angary) i Pyasina [Typical water levels of rivers, canals, lakes and reservoirs (year data). P. 1. Rivers and canals. Iss. 12. Basins of the Yenisei (without the Angara basin) and Pyasina]. Leningrad, Gidrometeoizdat Publ., 1989. 108 p.

31. Ezhegodnye dannye $v$ rezhime $i$ resursakh poverkhnostnykh vod sushi: Ch. 1. Reki i kanaly. T. 1: Vyp. 12. Basseyny Yeniseya (bez basseyna Angary) i Pyasina [Annual data of surface water regime and resources: P. 1. Rivers and canals. Vol. 1. Iss. 12. Basins of the Yenisei (without the Angara basin)]. Leningrad, Gidrometeoizdat Publ., 1966-1987.

32. Mohammed A.A., Pavlovskii I., Cey E.E., Hayashi M. Effects of preferential flow on snowmelt partitioning and groundwater recharge in frozen soils. Hydrology and Earth System Science, 2019, vol. 23, pp. 5017-5031. Available at: https://doi.org/10.5194/hess23-5017-2019 (accessed: 13 December 2020).

33. Iwata Y., Hayashi M., Suzuki S., Hirota T., Hasegawa S. Effects of snow cover on soil freezing, water movement, and snowmelt infiltration: a paired plot experiment. Water resources research, 2010, vol. 46, no. 9. Available at: https://doi.org/10.1029/2 009WR008070 (accessed: 13 December 2020)

34. Fu Q., Hou R., Li T., Jiang R., Yan P., Ma Z., Zhou Z. Effects of soil water and heat relationship under various snow cover during freezing-thawing periods in Songnen Plain, China. Scientific Reports, 2018, vol. 8, no. 1. Available at: https://doi.org/10.1038/ s41598-018-19467-y (accessed: 13 December 2020).

35. Du X., Fang M., Lv H., Cheng T., Hong P., Liu C. Effect of snowmelt infiltration on groundwater recharge in a seasonal soil frost area: a case study in Northeast China. Environmental Monitoring and Assessment, 2019, vol. 191, no. 3. Available at: https://doi.org/10.1007/s10661-019-7285-7 (accessed: 13 December 2020).

36. Silvestro F., Rebora N. Impact of precipitation forecast uncertainties and initial soil moisture conditions on a probabilistic flood forecasting chain. Journal of Hydrology, 2014, vol. 519, pp. 1052-1067.

37. Galakhov V.P., Mardasova E.V., Lyutsiger N.V., Samoilova S.Yu. Influence of fall freezing on maximum levels of Charysh River basin. Bulletin of the Altay branch of the Russian geographical society, 2018, vol. 48, no. 1, pp. 54-57. In Rus.

38. Burakov D.A., Ivanova O.I. The analysis of formation and the forecast of a drain of a spring high water in wood and forest-steppe pools of the rivers of Siberia. Russian meteorology and hydrology, 2010, vol. 35 , no. 6, pp. 421-431.

39. Galakhov V.P., Lovtskaya O.V., Mardasova E.V. Climate change effect on maximum flood stages in Abakan River. Bulletin of the Tomsk Polytechnic University. Geo Assets Engineering, 2021, vol. 332, no. 3, pp. 218-228. In Rus.

40. Galakhov V.P., Samoylova S.Yu., Mardasova E.V. Effect of a ratio of large morphological units of a mountain basin on snowmelt runoff (The Anui river basin as a case study). Bulletin of the Altay branch of the Russian geographical society, 2020, vol. 56, no. 1, pp. 24-33. In Rus.

Received: 2 February 2022.

\section{Information about the authors}

Vladimir P. Galakhov, Cand. Sc., senior researcher, Institute for Water and Environmental Problems SB RAS.

Olga V. Lovtskaya, senior researcher, Institute for Water and Environmental Problems SB RAS.

Svetlana Yu. Samoilova, Cand. Sc., researcher, Institute for Water and Environmental Problems SB RAS.

Elena V. Mardasova, senior lecturer, Altai State University. 